\title{
CD8 Positive T Cells Influence Antigen-Specific Immune Responses through the Expression of Chemokines
}

\author{
Jong J. Kim, ${ }^{\star}$ Liesl K. Nottingham, ${ }^{\S}$ Jeong I. Sin, ${ }^{\ddagger}$ Anthony Tsai, ${ }^{\ddagger}$ Lake Morrison, ${ }^{\ddagger}$ Jim Oh, ${ }^{\ddagger}$ Kesen Dang, ${ }^{\S}$ Yin Hu, ${ }^{\S}$ \\ Ken Kazahaya, ${ }^{\S}$ Mosi Bennett, ${ }^{\ddagger}$ Tzvete Dentchev, ${ }^{\ddagger}$ Darren M. Wilson, ${ }^{\ddagger}$ Ara A. Chalian, $\$$ Jean D. Boyer, ${ }^{\ddagger}$ Michael G. Agadjanyan, ${ }^{\ddagger}$ \\ and David B. Weiner \\ *Department of Chemical Engineering, ${ }^{\ddagger}$ Department of Pathology and Laboratory Medicine, ${ }^{\S}$ Department of Otolaryngology/Head and \\ Neck Surgery, University of Pennsylvania
}

\section{Abstract}

The potential roles of $\mathrm{CD}^{+} \mathrm{T}$-cell-induced chemokines in the expansion of immune responses were examined using DNA immunogen constructs as model antigens. We coimmunized cDNA expression cassettes encoding the $\alpha$-chemokines IL-8 and SDF- $1 \alpha$ and the $\beta$-chemokines MIP-1 $\alpha$, RANTES, and MCP-1 along with DNA immunogens and analyzed the resulting antigen-specific immune responses. In a manner more similar to the traditional immune modulatory role of $\mathrm{CD}^{+} \mathrm{T}$ cells via the expression of Th1 or Th2 cytokines, $\mathrm{CD}^{+} \mathrm{T}$ cells appeared to play an important role in immune expansion and effector function by producing chemokines. For instance, IL-8 was a strong inducer of $\mathrm{CD}^{+} \mathrm{T}$ cells, indicated by strong $\mathrm{T}$ helper proliferative responses as well as an enhancement of antibody responses. MIP-1 $\alpha$ had a dramatic effect on antibody responses and modulated the shift of immune responses to a Th2-type response. RANTES coimmunization enhanced the levels of antigen-specific Th1 and cytotoxic T lymphocyte (CTL) responses. Among the chemokines examined, MCP-1 was the most potent activator of $\mathrm{CD}^{+} \mathrm{CTL}$ activity. The enhanced CTL results are supported by the increased expression of Th1 cytokines IFN- $\gamma$ and TNF- $\alpha$ and the reduction of IgG1/IgG2a ratio. Our results support that $\mathrm{CD}^{+} \mathrm{T}$ cells may expand both humoral and cellular responses in vivo through the elaboration of specific chemokines at the peripheral site of infection during the effector stage of the immune response. (J. Clin. Invest. 1998. 102:1112-1124.) Key words: chemokines $\cdot$ DNA immunization $\cdot \mathrm{CD}^{+} \mathrm{T}$ effector cells $\bullet$ humoral and cellular immune response

\section{Introduction}

The adaptive immune response is a critical part of host defense against pathogens. The immune response is initiated when local inflammation induces tissue macrophages to produce proinflammatory cytokines and chemokines. Collectively,

Address correspondence to David B. Weiner, Department of Pathology and Laboratory Medicine, University of Pennsylvania, 505 Stellar-Chance, 422 Curie Blvd., Philadelphia, PA 19104. Phone: 215-3498365; FAX: 215-573-9436; E-mail: dbweiner@mail.med.upenn.edu

Received for publication 13 May 1998 and accepted in revised form 22 July 1998

J. Clin. Invest.

(C) The American Society for Clinical Investigation, Inc. 0021-9738/98/09/1112/13 \$2.00

Volume 102, Number 6, September 1998, 1112-1124

http://www.jci.org these molecules recruit more phagocytic cells and professional antigen-presenting cells (APCs) ${ }^{1}$ to the site of infection. Once attracted to the infection site, APCs ingest pathogenic antigens and transport them to local lymphoid organs. In the lymphoid organs, APCs process and present these antigens to naive $\mathrm{T}$ cells. When activated, $\mathrm{CD} 4^{+} \mathrm{T}$ helper cells modulate the level and the direction of immune response through the release of Th1- or Th2-type cytokines. T helper cells activate B lymphocytes to produce antigen-specific antibodies, which engages the humoral response. T helper cells also help cytotoxic T lymphocytes to search out and destroy infected cells in the periphery. Once engaged, humoral or cellular immunity can act independently or in concert to eradicate the pathogenic organism from the host.

Although the importance of modulatory signals from $\mathrm{T}$ helper cells in directing the immune response is well appreciated, the role of signaling from $\mathrm{CD}^{+} \mathrm{T}$ cells is not known. Cytotoxic $\mathrm{T}$ cells bind and destroy allogeneic and virally infected cells that display recognizable antigen-MHC class I molecules. Killer $\mathrm{T}$ cells induce these pathogen-infected cells to die through either the release of toxic proteins such as granzyme B or through initiating apoptosis or programmed cell death in the target cells. In addition to the direct killing of the infected cells, $\mathrm{CD}^{+} \mathrm{T}$ cells may provide additional signals to other lymphocyte subsets to help amplify and direct the immune response in the periphery. These signals importantly might include the highly bioactive inflammatory molecules termed chemokines. Chemokines play a major role in a variety of immune and inflammatory responses, acting primarily as chemoattractants and activators of various leukocytes $(1,2)$. For example, in response to pathogens, tissue macrophages initiate host immune responses by producing chemokines. These chemokines in turn attract more leukocytes to the site of infection and tissue damage.

Chemokines are broadly divided into three families, $\mathrm{C}-\mathrm{X}-\mathrm{C}$ $(\alpha)$, C-C $(\beta)$, and $C(\gamma)$, based on the presence and position of the conserved cysteine residues (3). In the members of the $\alpha$ family, the first two cysteines are separated by another amino acid, while those of the $\beta$ family are placed next to each other (3). Only two members of the $\gamma$ family have been identified so far, and both of them contain one instead of two cysteines in their $\mathrm{N}$ terminus (3). Overall, there are many chemokines with seemingly overlapping functions, and the exact role of each one in host defense and in pathological responses is not well known. Recently the role of $\mathrm{CD}^{+} \mathrm{T}$ cells in the production of chemokines has been appreciated (4-8). Their additional function in such immune expansion is unclear.

1. Abbreviations used in this paper: APC, antigen-presenting cells; CTL, cytotoxic T lymphocyte; NK, natural killer; RD, rhabdomyosarcoma. 
During evaluation of host immune responses induced by DNA vaccines for HIV-1 antigens, we observed that in addition to eliciting both humoral and cell-mediated immune responses, DNA vaccination induced $\beta$-chemokine expression in $\mathrm{CD}^{+} \mathrm{T}$ lymphocytes. The temporal nature of these results implied that chemokines may be important activators of immune responses. To molecularly dissect the specific roles of chemokines in immune response, we cloned representative cDNAs encoding the $\alpha$-chemokines IL- 8 and SDF- $1 \alpha$ as well as cDNAs encoding the $\beta$-chemokines MIP-1 $\alpha$, RANTES, and MCP-1. These inserts were cloned individually into expression vectors and coimmunized along with DNA immunogens encoding for HIV-1 envelope or gag/pol antigens. These chemokines are especially relevant since they are produced by activated $\mathrm{T}$ lymphocytes. Using these vaccine constructs as model antigens, we observed that individual chemokines had specific, identifiable roles in the activation and modulation of antigen-specific immune responses. The observation that $\mathrm{CD}^{+}$effector cells elevated chemokine expression levels while they primed immune responses suggests a regulatory role for these end-stage effector cells in the expansion phase of an antigen-specific immune response. These results conceptually link lymphocyte activation and expansion driven by $\mathrm{CD}^{+} \mathrm{T}$ cells within the lymphoid compartments such as the lymph nodes and spleen with lymphocyte expansion, tissue invasion, and effector function modulated at least in part by $\mathrm{CD}^{+}$effector $\mathrm{T}$ cells in the periphery.

\section{Methods}

DNA plasmids. DNA vaccine constructs expressing HIV-1 envelope protein (pCEnv) and gag/pol protein ( $\mathrm{pCGag} / \mathrm{Pol}$ ) were prepared as previously described (9). The genes for human chemokines IL-8, SDF- $1 \alpha$, MIP- $1 \alpha$, MCP-1, and RANTES were cloned into the pCDNA3 expression vector (Invitrogen, Inc., San Diego, CA) as previously described $(10,11)$. Clean plasmid DNA was produced in bacteria and purified using Qiagen Maxi Prep kits (Qiagen, Santa Clara, CA).

Reagents and cell lines. Human rhabdomyosarcoma (RD) and mouse mastocytoma P815 cell lines were obtained from ATCC (Rockville, MD). Recombinant vaccinia expressing HIV-1 envelope (vMN462), gag/pol (vVK1), and $\beta$-galactosidase (vSC8) were obtained from the NIH AIDS Research and Reference Reagent Program. HIV-1 envelope peptide (RIHIGPGRAFYTTKN) was synthesized according to the previously published protocol (12). Recombinant gp120 or p24 protein were obtained from ImmunoDiagnostics, Inc. (Bedford, MA).

DNA inoculation of mice. The quadriceps muscles of 6-8-wk-old female BALB/c mice (Harlan Sprague Dawley, Inc., Indianapolis, IN) were injected with $50 \mu \mathrm{g}$ of each DNA construct of interest formulated in PBS and $0.25 \%$ bupivacaine- $\mathrm{HCl}$ (Sigma Chemical Co., St. Louis, MO). Coadministration of various gene expression cassettes involved mixing the chosen plasmids before injection. The control mice were immunized with $50 \mu \mathrm{g}$ of pCDNA3 vector. Each set of studies was performed three times, and a representative set of results is presented. Mice received two DNA immunizations (50 $\mu \mathrm{g}$ each) separated by $2 \mathrm{wk}$. At $1 \mathrm{wk}$ after the boost injection, the mice were killed, the spleens were harvested, and the lymphocytes were isolated and tested for cellular (Th or cytotoxic T lymphocyte [CTL]) responses. All animals were housed in a temperature-controlled, lightcycled facility at the University of Pennsylvania, and their care was under the guidelines of the National Institutes of Health and the University of Pennsylvania.

In vivo expression of chemokine gene constructs. The quadriceps muscles of mice were injected with $50 \mu \mathrm{g}$ of MIP-1 $\alpha$, RANTES, MCP-1, SDF-1 $\alpha$, and irrelevant control constructs formulated in PBS and $0.25 \%$ bupivacaine- $\mathrm{HCl}$. The mice were killed and their leg muscle was removed $3 \mathrm{~d}$ after injection. The muscle was dissected, minced, and placed in tissue culture for 3 additional days. The supernatant was collected and tested for chemokine expression using the ELISA kit for MIP-1 $\alpha$, RANTES, and MCP-1 (Intergen, Purchase, NY).

ELISA. ELISA for mouse antisera was performed as previously described (10). For the determination of relative levels of gp120-specific IgG subclasses, antimurine $\operatorname{IgG} 1$ and $\operatorname{IgG} 2$ a conjugated with HRP (Zymed, San Francisco, CA) were substituted for antimurine IgG-HRP. This was followed by addition of the ABTS substrate solution (Chemicon, Temecula, CA).

Thelper cell proliferation assay. $\mathrm{T}$ helper cell proliferation assay was performed as previously described (10).

Cytotoxic T lymphocyte assay. A 5-h ${ }^{51} \mathrm{Cr}$ release $\mathrm{CTL}$ assay was performed using vaccinia-infected targets or peptide-treated targets as previously described (10).

Complement lysis of $\mathrm{CD}^{+} \mathrm{T}$ cells. Complement lysis of $\mathrm{CD}^{+} \mathrm{T}$ cells was performed as previously described (10).

Cytokine and chemokine expression analysis. Supernatants from effectors stimulated for CTL assay were collected at day 6 and tested for cytokine profile using ELISA kits for IFN- $\gamma$, IL-4, and TNF- $\alpha$ (Biosource International, Inc., Camarillo, CA). Supernatants from stimulated effector cells were also tested for chemokine profile using chemokine ELISA kits for MIP-1 $\alpha$ (R\&D Systems, Minneapolis, MD), RANTES, and MCP-1 (Intergen).

\section{Results}

Induction of chemokines by DNA vaccination. Mice were immunized with $50 \mu \mathrm{g}$ of pCDNA3 (control), pCEnv, or pCGag/ pol. After $2 \mathrm{wk}$, animals were killed, their spleens were harvested, and their lymphocytes were isolated and stimulated in a standard CD8 effector CTL assay $(10,11,13)$. We collected the culture supernatant from the cultures and tested them for the release of chemokines MIP- $1 \alpha$, MIP-1 $\beta$, and RANTES. We observed that DNA immunization with pCEnv or pCGag/pol induced significantly greater levels of expression of $\beta$-chemokines MIP-1 $\alpha$, MIP-1 $\beta$, and RANTES over those of control vector as shown in Fig. $1 A-C$, respectively. MIP- $1 \alpha$, MIP- $1 \beta$, and RANTES were increased three- to fivefold. The increase was present as early as $2 \mathrm{wk}$ after the first immunization and coordinated with the observed $\mathrm{T}$ cell and humoral responses, suggesting that these chemokines could be modulating immune responses in vivo. To determine the effects of the chemokines on antigen-specific responses, we next investigated their effects on immune responses induced by the model DNA vaccine.

Construction of chemokine expression cassettes. The cDNAs for human chemokines IL-8, SDF- $1 \alpha$, MIP- $1 \alpha$, MCP-1, and RANTES were individually cloned into pCDNA3 plasmid expression vectors by using methods previously described (10, 11, 13). Human SDF- $1 \alpha$, MIP- $1 \alpha$, MCP-1, and RANTES have been reported to be active in mouse cells (14). The mouse homologue of human IL- 8 has not been found; however, human IL-8 has been reported to have activity on mouse cells as a subset of the receptors for IL-8 is expressed on mouse cells (14). These chemokine expression cassettes were verified by sequencing analysis of the entire insert (including both $5^{\prime}$ and 3 ' flanking sequences). In addition, chemokine constructs were transfected in vitro into RD cells, and the expression of these constructs was verified by immunoprecipitation using relevant antibodies or by specific chemokine ELISA (data not shown). The expression constructs for IL-8, SDF- $1 \alpha$, MIP- $1 \alpha$, MCP-1, and RANTES were also tested for in vivo expression in mouse muscle. As presented in Fig. 2, the constructs expressed their 
A

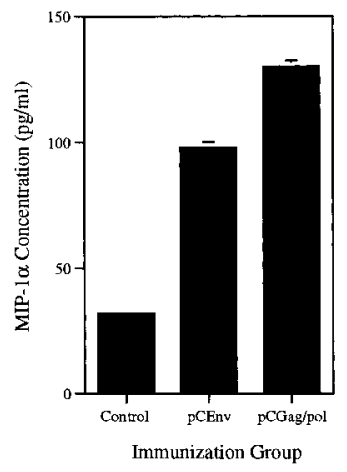

B

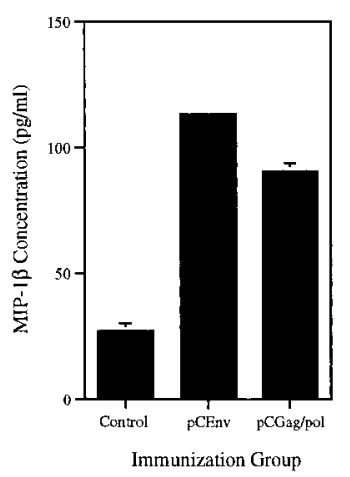

C

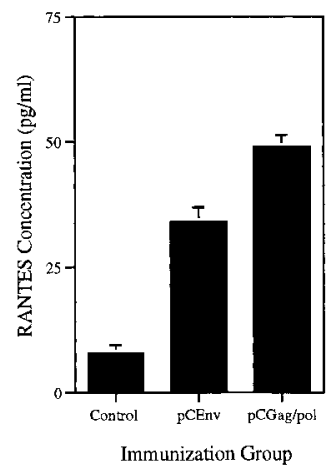

Figure 1. Induction of chemokines by DNA vaccination. Mice were immunized with $50 \mu \mathrm{g}$ of pCDNA3 (Control), pCEnv, or $\mathrm{pCGag} / \mathrm{pol}$. After $2 \mathrm{wk}$, the mice were killed, the spleens were harvested, and the lymphocytes were isolated. These cells were stimulated in vitro with specific stimulation (using vaccinia infected stimulators) for $5 \mathrm{~d}$. The culture supernatants from the effector cells were collected and were tested for the release of MIP-1 $\alpha(A)$, MIP$1 \beta(B)$, and RANTES $(C)$. respectively encoded chemokines in mouse muscle tissue in vivo at $3 \mathrm{~d}$ after transfection. Mice were immunized intramuscularly with $50 \mu \mathrm{g}$ of pCMIP- $1 \alpha$ or pCRANTES or pCDNA3 (control). The mice were killed, and their leg muscle was removed 3 after injection. The muscle tissues were mechanically pulverized and were cultured in vitro for $72 \mathrm{~h}$ and the supernatants were tested for the expression using the ELISA kits for MIP- $1 \alpha$ and RANTES. The expression of MCP-1 construct was similarly confirmed (data not shown).

IL-8 enhances T cell proliferation and Th1 isotype. The effects of various chemokines on vaccine-induced responses were analyzed individually. IL-8 is a potent chemotactic factor for neutrophil granulocytes and lymphocytes, and it is secreted by a variety of cell types, including T cells $(15,16)$. IL- 8 binds to CXCR1, which is expressed on neutrophils, monocytes, and $\mathrm{CD}^{+} \mathrm{T}$ cells $(17,18)$. The first immune parameter examined was the antigen-specific humoral response. Antisera from pCEnv and pCEnv+IL-8 immunized mice was collected and analyzed for specific antibody responses against HIV-1 gp120 protein by ELISA. Fig. $3 A$ shows the gp120-specific antibody titer from sera collected at weeks $0,2,4$, and 6 after DNA immunization. At 1:128 dilution, sera from the groups immunized with pCEnv+IL-8 showed antibody response against gp120 protein, which was greater than that of the group immunized with pCEnv alone. A similar result was seen with the groups immunized with pCGag/pol (data not shown). Furthermore, the subclasses of gp120-specific IgGs induced by the coadministration with IL-8 genes were determined. It has been reported that production of IgG1 type is induced by Th2-type cytokines, whereas the IgG2a-type production is induced by Th1-type cytokines (19). The relative ratios of $\mathrm{IgG} 1$ to $\mathrm{IgG} 2 \mathrm{a}$ (Th2 to Th1) are shown in Fig. 3 B. The pCEnv immunized group had a $\mathrm{IgG} 1$ to $\mathrm{IgG} 2 \mathrm{a}$ ratio of 1.3. On the other hand, coinjection with pCEnv+IL-8 decreased the relative ratio to 0.9 , indicating a shift to Th1-type response.

The effect of IL-8 expression on the T helper cell-proliferative response was also examined. As shown in Fig. 3, $C$ and $D$, IL-8 coexpression with HIV-1 immunogens (pCEnv or $\mathrm{pCGag} / \mathrm{pol}$ ) resulted in a dramatic level of antigen-specific $\mathrm{T}$ helper cell-proliferative responses. The increase in proliferation was between four- and sixfold, a significant increase in antigen-specific responses. In addition, the effect of IL-8 coexpression on the induced CTL response was also investigated. As shown in Fig. $3 E$, a background level of specific killing was observed from the control animals, whereas the animals immunized with pCEnv alone showed a small but consistent level of
A

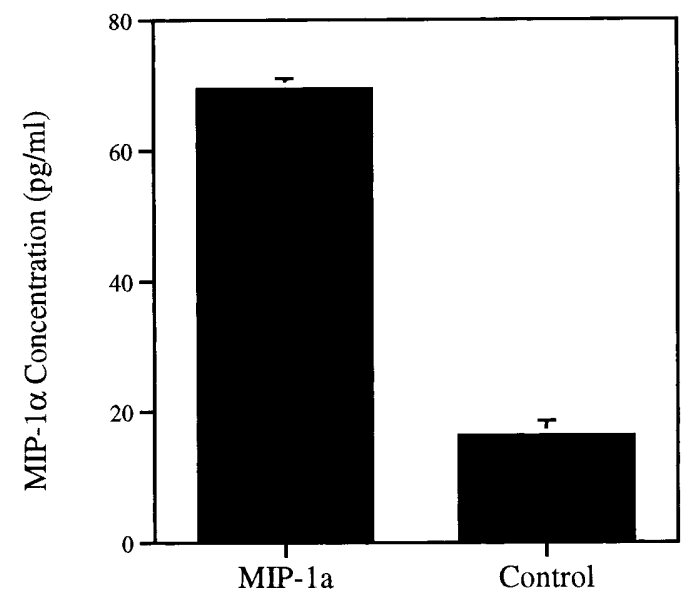

Transfection Group

B

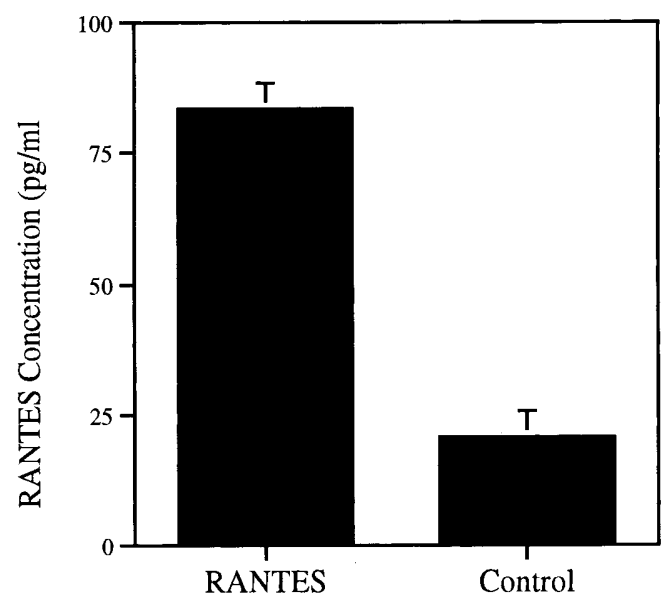

Transfection Group

Figure 2. In vivo expression of the chemokine constructs. Mice were immunized intramuscularly with $50 \mu \mathrm{g}$ of pCMIP- $1 \alpha(A)$ or pCRANTES $(B)$ or pCDNA3 (Control). The mice were killed, and their leg muscles were removed $3 \mathrm{~d}$ after injection. The muscle tissues were cultured in vitro for $72 \mathrm{~h}$, and the supernatant were tested for the expression using the ELISA kits for MIP-1 $\alpha(A)$ and RANTES $(B)$. 
A

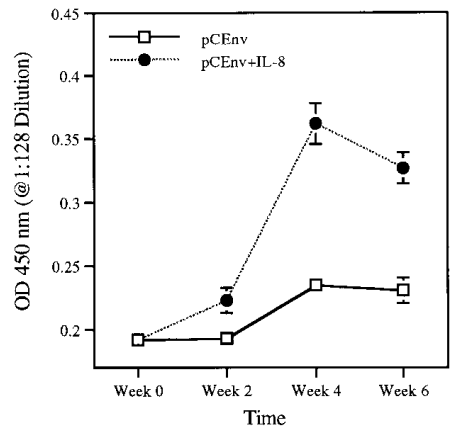

C

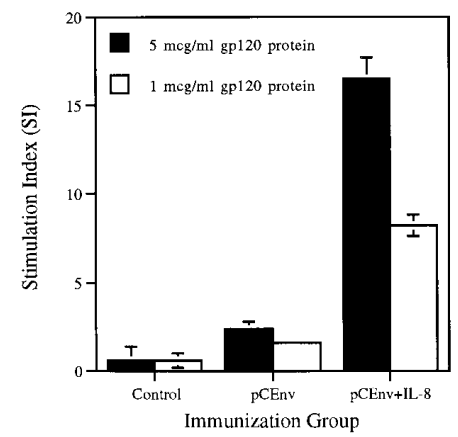

E

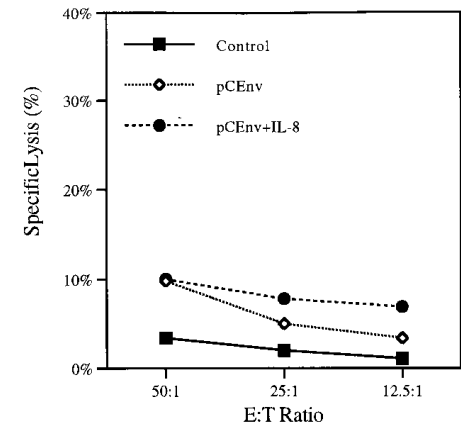

B

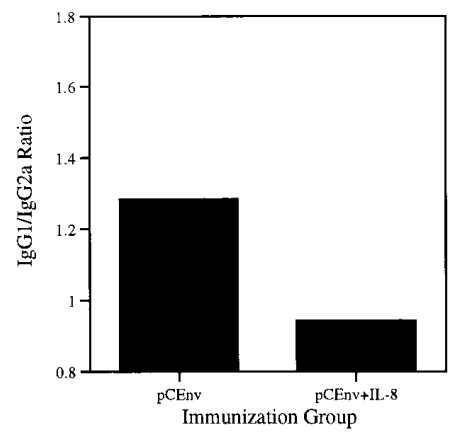

D

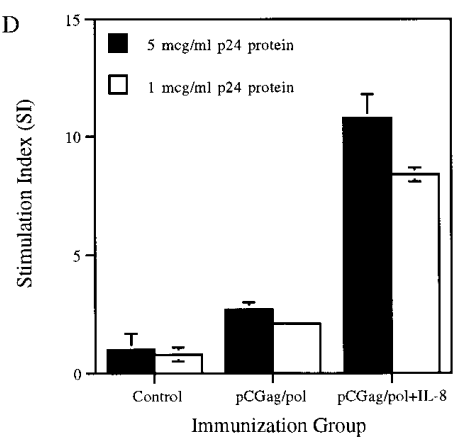

F

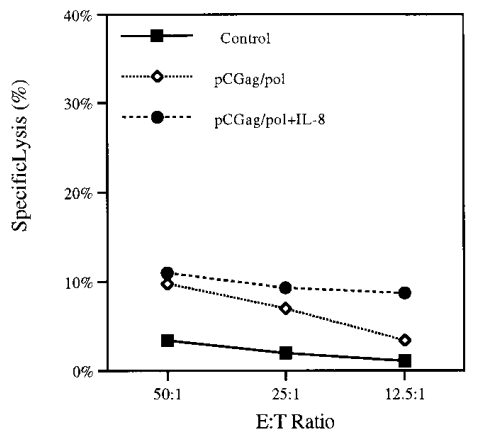

G

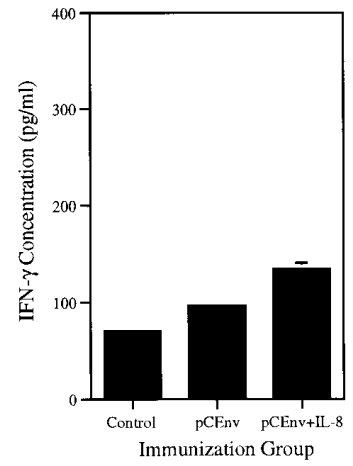

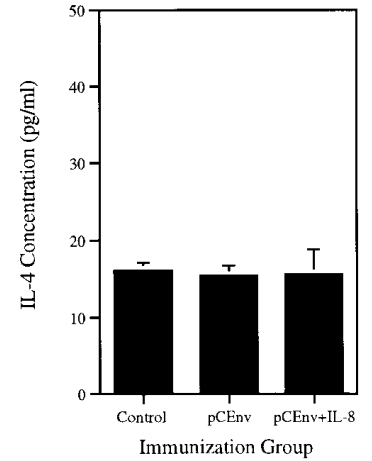

Immunization Group

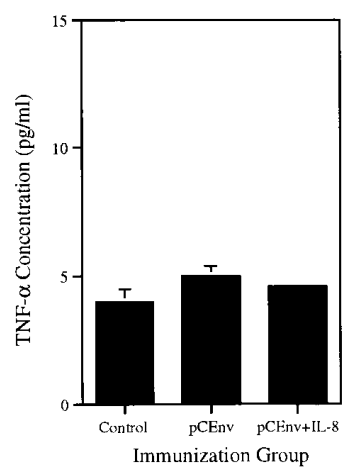

Figure 3. Antigen-specific immune responses after coimmunization with IL-8. Mice were coimmunized with $50 \mu \mathrm{g}$ each of IL-8 and pCEnv expression cassettes intramuscularly at weeks 0 and 2. (A) HIV-1 envelope-specific antibody response after coimmunization. (B) HIV-1 envelope-specific IgG1/IgG2a ratio following coimmunization (at week 6). (C) HIV-1 envelope-specific Th cell-proliferative response after coimmunization. (D) HIV-1 gag/pol-specific Th cell-proliferative response following coimmunization. (E) HIV-1 envelope-specific CTL response after coimmunization. (F) HIV-1 gag/pol-specific CTL response after coimmunization. ( $G$ ) Induction of cytokines IFN- $\gamma$, IL-4, and TNF- $\alpha$ in the supernatant of stimulated effector cells. These experiments have been repeated two times with similar results.
CTL response. IL-8 coadministration did not have any enhancement effect on the antigen-specific CTL response. Similar CTL results were observed from pCGag/pol+IL-8 coimmunization (Fig. 3 F).

Cytokines play a key role in directing and targeting immune cells during the development of the immune response. For instance, IFN- $\gamma$ is intricately involved in the regulation of $\mathrm{T}$ cell-mediated cytotoxic immune responses (20), while IL-4 plays a dominant role in $\mathrm{B}$ cell-mediated immune responses (21). TNF- $\alpha$ is produced by activated macrophages and mono- cytes, neutrophils, activated lymphocytes, and natural killer (NK) cells, and has been suggested to play a pivotal role in regulating the synthesis of other proinflammatory cytokines (22). We analyzed supernatant from the effector cells stimulated in vitro for CTL assay and tested them for the release of cytokines IFN- $\gamma$, IL-4, and TNF- $\alpha$. We found that IL-8 expression increased the level of IFN- $\gamma$ only slightly, but it did not affect the levels of cytokines IL-4 and TNF- $\alpha$ (Fig. $3 G$ ).

$S D F-1 \alpha$ drives immune responses towards Th1-type immunity. We next examined the effects of SDF-1 $\alpha$ codelivery on 
vaccine induced immune responses. SDF- $1 \alpha$ is a $\mathrm{C}-\mathrm{X}-\mathrm{C}$ chemokine, which binds to the CXCR4 (LESTR/fusin) receptor $(4,5)$. CXCR4 is expressed on a variety of leukocytes including monocytes/macrophages, neutrophils, B cells, and $\mathrm{T}$ cells (23). It is also a main coreceptor for entry of T cell-tropic HIV-1 strains $(4,5)$. Unlike IL-8, SDF-1 $\alpha$ coinjection did not exhibit any effect on the level of antigen-specific humoral response (Fig. $4 \mathrm{~A}$ ). Moreover, the relative ratios of $\mathrm{IgG} 1$ to $\mathrm{IgG} 2 \mathrm{a}$ after the coadministration with $\mathrm{pCEnv}+\mathrm{SDF}-1 \alpha$ were determined and are shown in Fig. $4 \mathrm{~B}$. The pCEnv immunized group had a IgG1 to IgG2a ratio of 1.3. On the other hand, coinjection with $\mathrm{pCEnv}+\mathrm{SDF}-1 \alpha$ decreased the relative ratio to 1.08 , indicating a shift to Th1-type response. SDF-1 $\alpha$ coinjection with HIV-1 immunogens (pCEnv or pCGag/pol) had small enhancement effect on the level of antigen-specific $\mathrm{T}$ helper cell-proliferative responses (Fig. 4, $C$ and $D$ ). However, SDF- $1 \alpha$ immunization had minimal effect on the antigen-specific CTL responses (Fig. 4, $E$ and $F$ ) or on the induction of cytokines (Fig. $4 G$ ).

$M I P-1 \alpha$ is a strong expander of antibody response. MIP- $1 \alpha$ is a $\mathrm{C}-\mathrm{C}$ chemokine that binds to the receptors CCR1, CCR4, and CCR5. CCR1 is expressed on basophils and monocytes
A

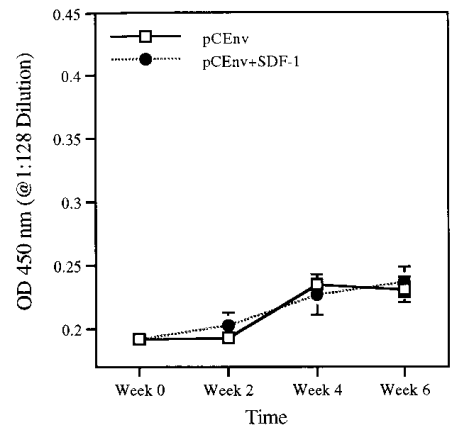

C
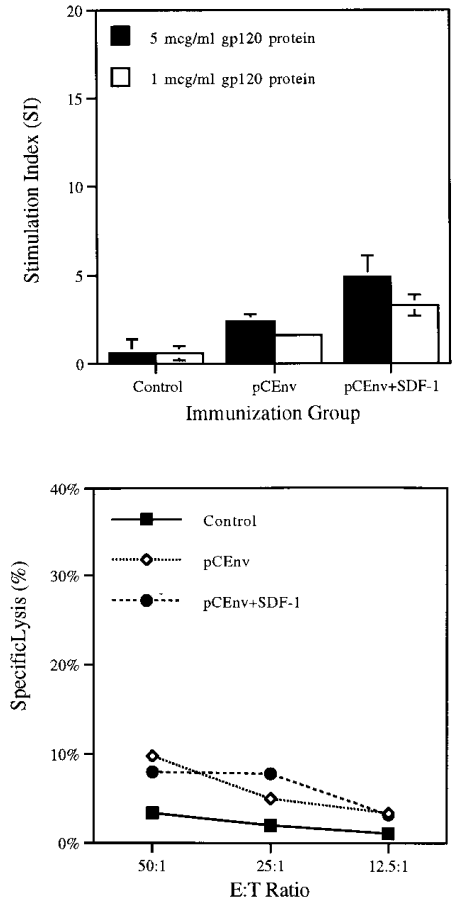

$B$
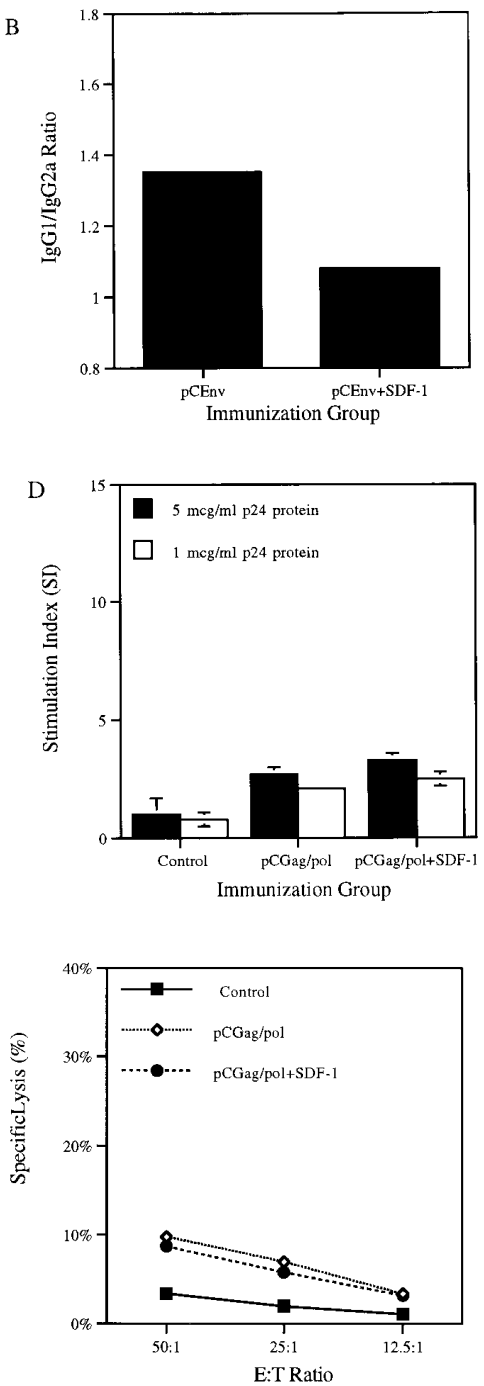

G
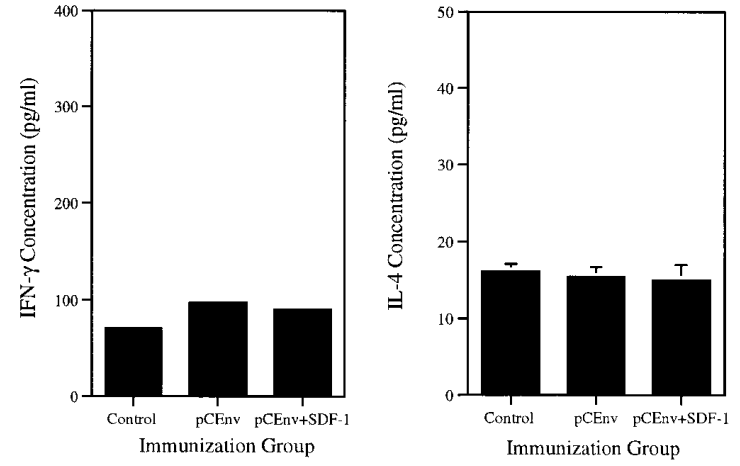

Figure 4. Antigen-specific immune responses after coimmunization with SDF- $1 \alpha$. 
while CCR4 is expressed on monocytes, T cells, and B cells (1). CCR5, which is expressed on monocytes and macrophages, is a main coreceptor for entry of macrophage-tropic HIV-1 strains (6-8). MIP-1 $\alpha$ coexpression exhibited a more drastic effect than IL- 8 in the induction of antigen-specific humoral responses (Fig. $5 A$ ). pCEnv+MIP- $1 \alpha$ coimmunization resulted in a dramatic enhancement of envelope-specific antibody response. A similar result was seen with the groups immunized with $\mathrm{pCGag} / \mathrm{pol}$ (data not shown). Moreover, the relative ratios of $\mathrm{IgG} 1$ to $\mathrm{IgG} 2 \mathrm{a}$ after the coadministration with
pCEnv + MIP- $1 \alpha$ were determined and are shown in Fig. 5 B. The pCEnv immunized group had a IgG1 to IgG2a ratio of 1.3. On the other hand, coinjection with pCEnv + MIP- $1 \alpha$ increased the relative ratio to 1.7 , indicating a shift to a more Th2-type response. MIP-1 $\alpha$ coexpression with HIV-1 immunogens (pCEnv or $\mathrm{pCGag} / \mathrm{pol}$ ) resulted in enhancement of antigen-specific T helper cell-proliferative responses (Fig. 5, $C$ and $D)$. In contrast, MIP- $1 \alpha$ immunization had minimal effect on the antigen-specific CTL responses (Fig. 5, $E$ and $F$ ) or the induction of cytokines (Fig. $5 G$ ).
A

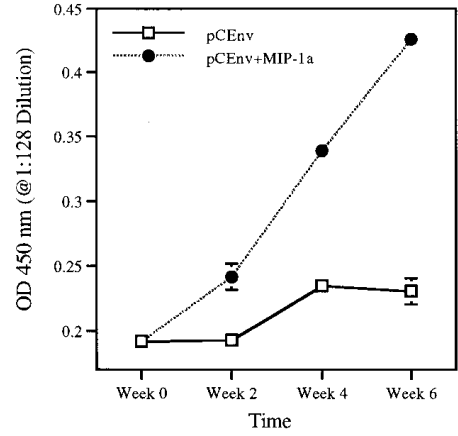

$\mathrm{C}$

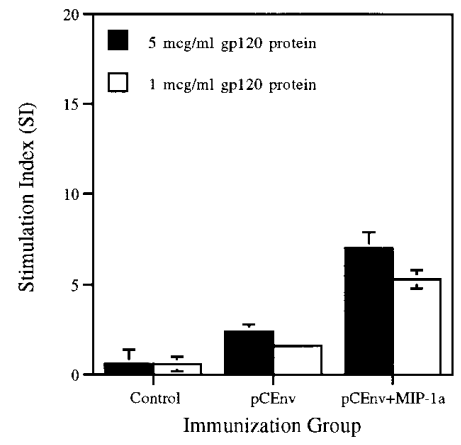

E

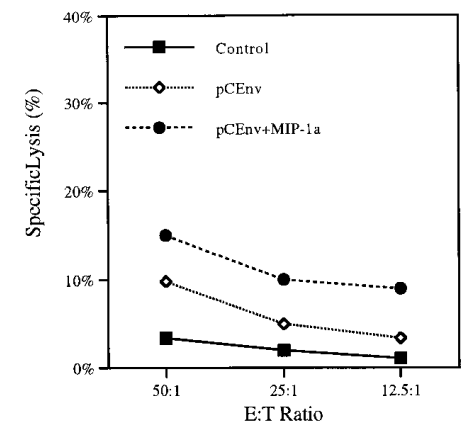

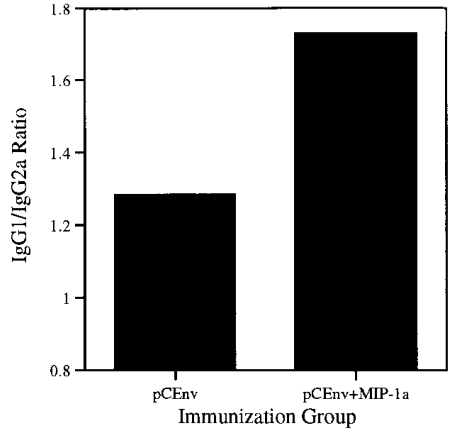
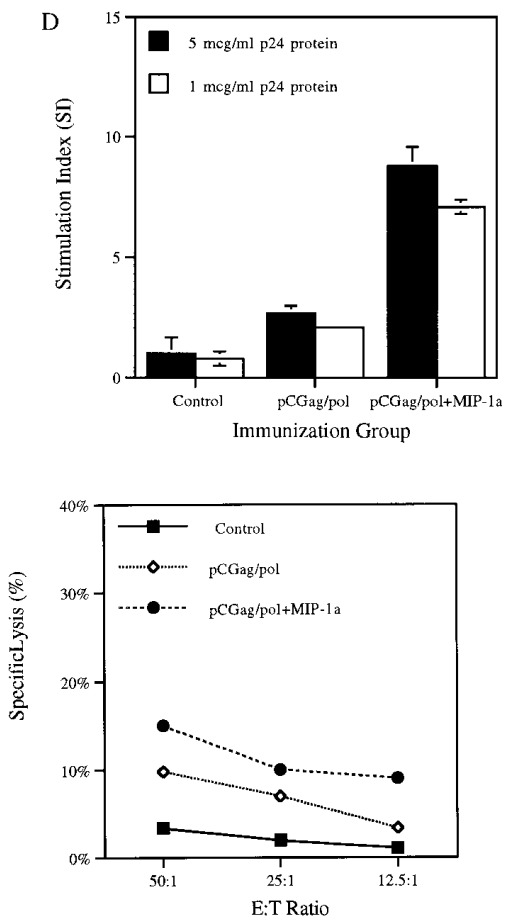

G

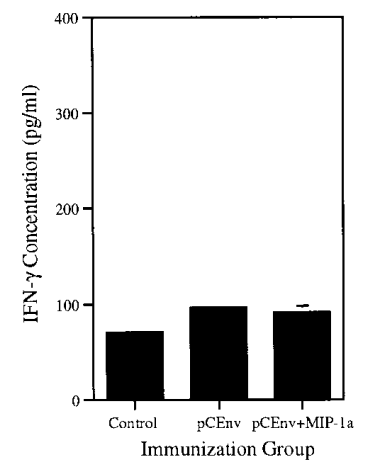

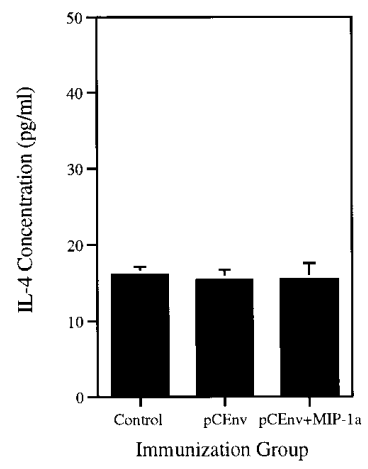

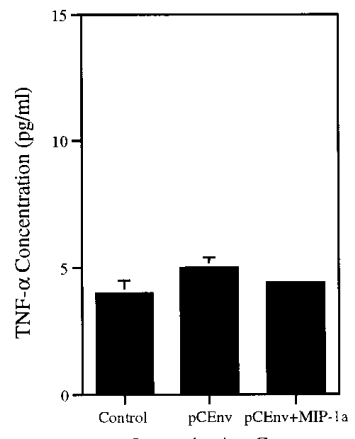

Immunization Group
Figure 5. Antigen-specific immune responses after coimmunization with MIP- $1 \alpha$. 
RANTES expands Th1 as well as CTL responses. We next examined the effects of RANTES codelivery on vaccineinduced immune responses. RANTES binds to the CCR1, CCR3, CCR4, and CCR5 receptors. CCR3 is expressed on eosinophils and monocytes. CCR3 is also a coreceptor for entry of macrophage-tropic HIV-1 strains, but it is less prominent than CCR5 $(24,25)$. Unlike IL-8 and MIP- $1 \alpha$, coexpression of RANTES with pCEnv did not significantly enhance HIV-1 envelope-specific antibody response (Fig. $6 A$ ). In addition, pCEnv+RANTES coimmunization did not have any effect on the $\mathrm{IgG} 1 / \mathrm{IgG} 2 \mathrm{a}$ ratio when compared with the group immunized with pCEnv alone (Fig. $6 B$ ). In contrast to the antibody responses, RANTES covaccination with HIV-1 immunogens (pCEnv or $\mathrm{pCGag} / \mathrm{pol}$ ) resulted in significant augmentation of antigen-specific $\mathrm{T}$ helper cell-proliferative responses (Fig. 6, $C$ and D). Furthermore, twofold higher level expression of Th1 cytokines IFN- $\gamma$ and TNF- $\alpha$ was observed from the group coadministered with pCEnv+RANTES (Fig. $6 G$ ). Unlike coinjection with pCEnv+IL-8 or pCEnv+MIP-1 $\alpha$, which resulted in a minimal effect in CTL activity, a more dramatic increase in the specific killing of targets infected with vaccinia (vMN462) expressing HIV-1 envelope was observed
A

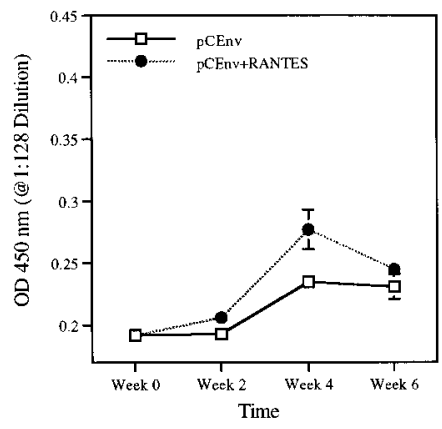

C

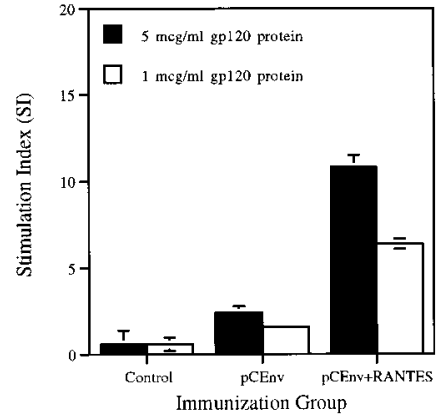

E

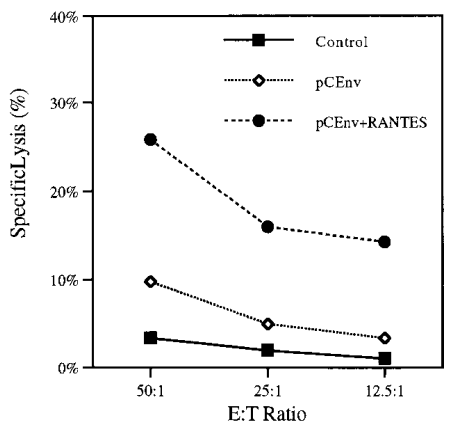

G

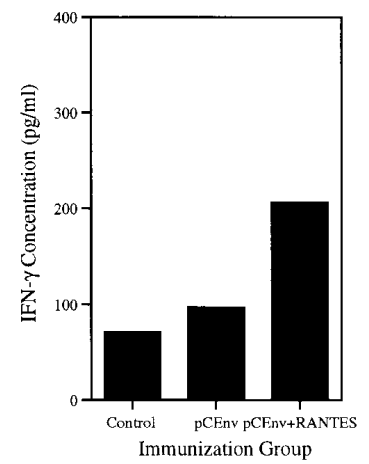

B

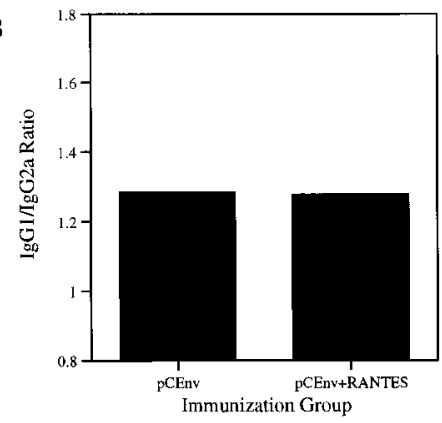

D

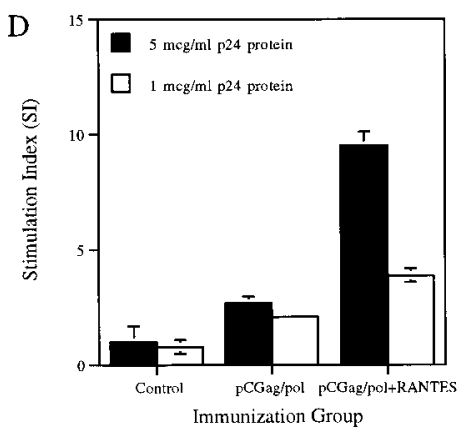

F

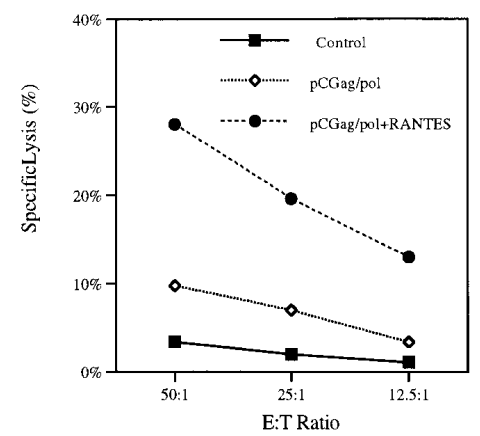

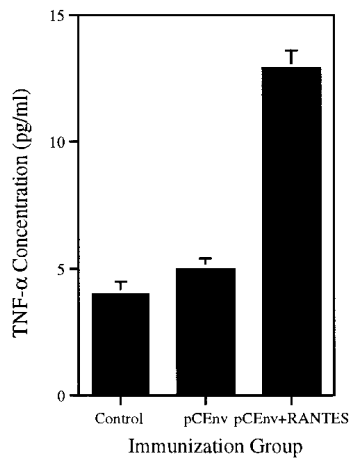

Figure 6. Antigen-specific immune responses after coimmunization with RANTES. 
after coinjection with pCEnv+RANTES (Fig. 6 E). Almost $30 \%$ specific lysis of target cells was observed after coinjection with pCEnv+RANTES at a 50:1 E/T ratio. Similarly, the mice immunized with pCGag/pol+RANTES resulted in a significant enhancement of antigen-specific CTL lysis of targets infected with vaccinia (vVK1) expressing HIV-1 gag/pol (Fig. $6 F$ ).

$M C P-1$ is a potent expander of CTL responses. Adjuvant properties of MCP-1 cDNA were next observed. MCP-1 is a $\mathrm{C}-\mathrm{C}$ chemokine that binds to the CCR2 receptor. Similar to
CCR3 and CCR5, CCR2 is a coreceptor for entry of macrophage-tropic HIV-1 strains, but it is less prominent than CCR5 (25). MCP-1 appeared to have a minimal effect on the specific antibody-binding profile induced by pCEnv immunization. Moreover, MCP-1 coexpression with HIV-1 immunogens (pCEnv or $\mathrm{pCGag} / \mathrm{pol}$ ) had positive but relatively minor (twofold) enhancement of antigen-specific $\mathrm{T}$ helper cell-proliferative responses (Fig. $7 A$ ). Furthermore, the relative ratios of IgG1 to IgG2a after the coadministration with pCEnv+MCP-1
A

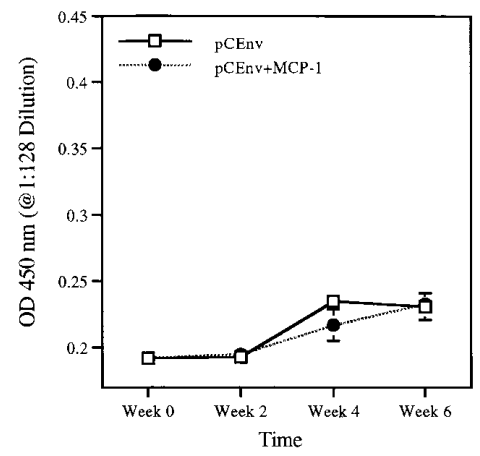

$\mathrm{C}$
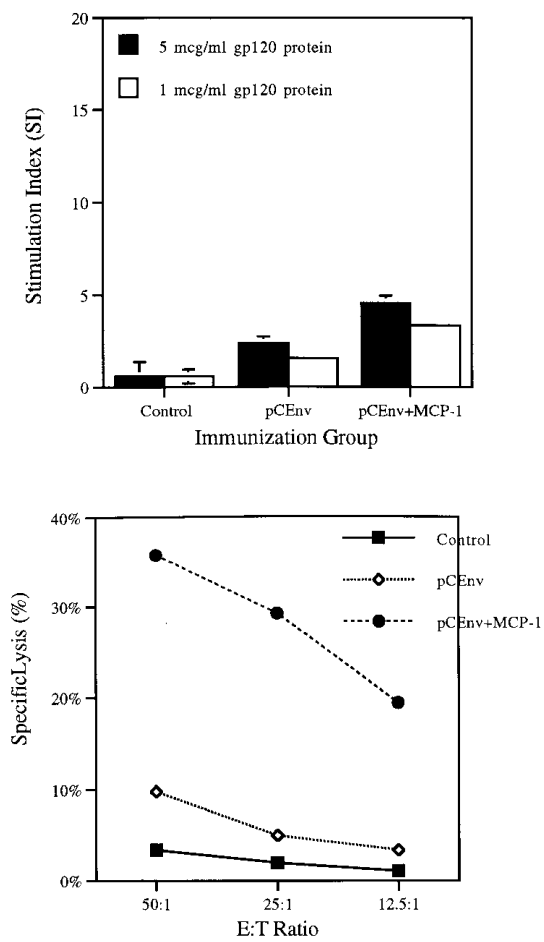

B
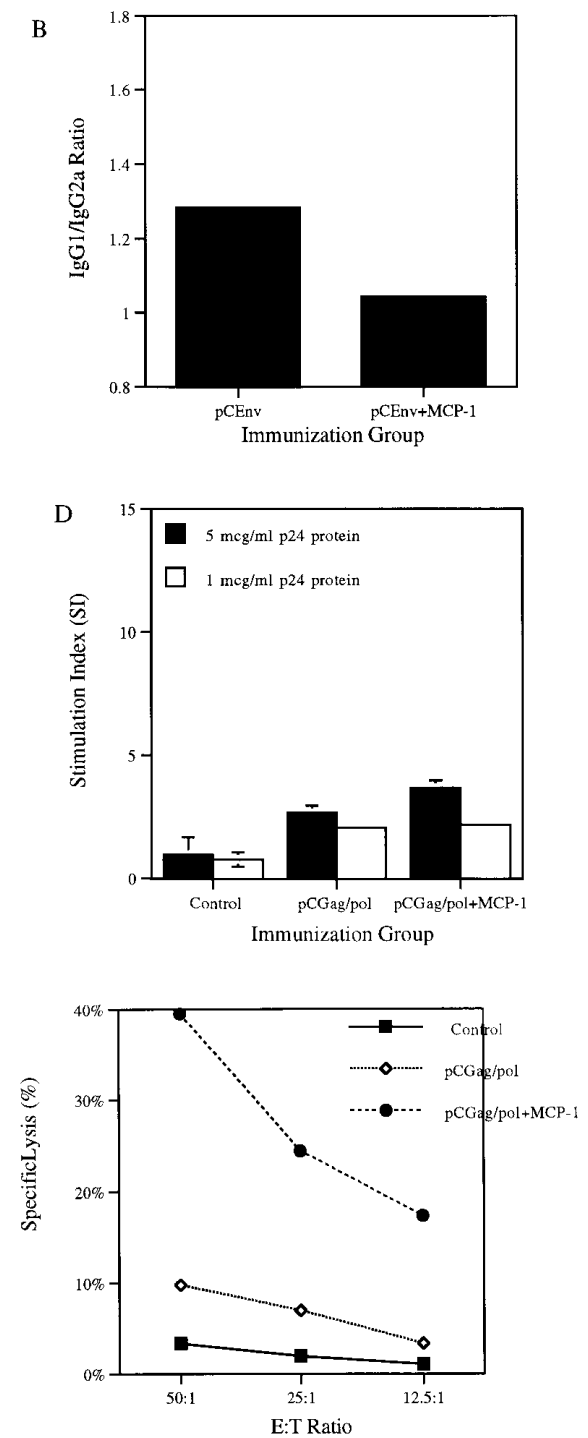

G

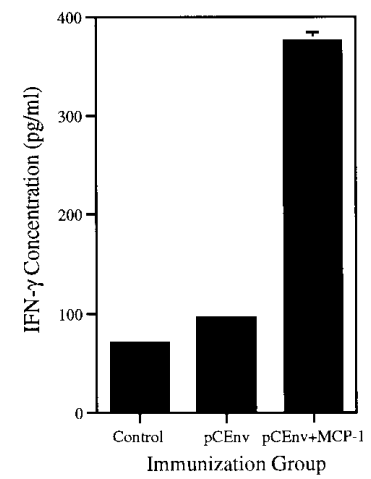

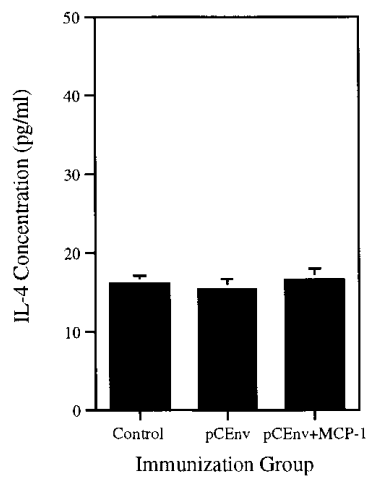

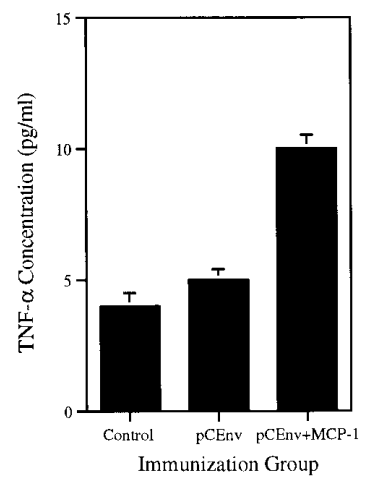

Figure 7. Antigen-specific immune responses after coimmunization with MCP-1. 
were determined and are shown in Fig. 7 B. The pCEnv immunized group had a $\operatorname{IgG} 1$ to $\operatorname{IgG} 2$ a ratio of 1.3 . On the other hand, coinjection with pCEnv $+\mathrm{MCP}-1$ decreased the relative ratio to 1.0 , indicating a shift to Th1-type response. A more dramatic increase in the specific killing was observed after coinjection with pCEnv $+\mathrm{MCP}-1$ (Figure 7 E). $>36 \%$ specific lysis of target cells was observed after coinjection with pCEnv + MCP-1 at a 50:1 E/T ratio. Similarly, the mice immunized with $\mathrm{pCGag} / \mathrm{pol}+\mathrm{MCP}-1$ resulted in a significant enhancement of antigen-specific CTL lysis of HIV-1 gag/pol expressing targets (Fig. $7 F$ ). As shown in Fig. $7 G$, the level of IFN- $\gamma$ release by mice immunized with pCEnv $+\mathrm{MCP}-1$ was significantly greater than those of the pCEnv immunized or the control groups. Again, the level of IL-4 released from all groups was similar. Moreover, the level of $\mathrm{TNF}_{-} \alpha$ release by pCEnv+MCP-1 immunized group was significantly greater than those of the pCEnv immunized or the control groups. These cytokine release data support the CTL above results implicating MCP-1 as an activator of $\mathrm{CD}^{+}$CTL.

Determination of $C D 8$ restriction in $C T L$ response. To determine whether the increases in CTL response via coexpression of MCP-1 and RANTES were restricted to $\mathrm{CD}^{+} \mathrm{T}$ cells, CTL assays were performed using a HIV-1 envelope peptide (RIHIGPGRAFYTTKN) pulsed cells as targets. This peptide has been shown to be a specific epitope for MHC class I-restricted CTL in Balb/c mice (12). Mice received two immunizations of $50 \mu \mathrm{g}$ of each DNA construct separated by $2 \mathrm{wk}$, and their spleens were harvested 1 wk after the second immunization. The CTL assay was performed on the splenocytes after in vitro stimulation with envelope-specific peptides as previously described $(10,11)$. We observed a significant enhancement of CTL response after coinjection (Fig. 8) with MCP-1 and RANTES at 35 and 26\% specific killing at an E/T ratio of $50: 1$, respectively. We verified this observation by measuring CTL activity after the removal of $\mathrm{CD}^{+} \mathrm{T}$ cells from the effector cell population by complement lysis (10). As shown in Fig. 9, the removal of $\mathrm{CD}^{+} \mathrm{T}$ cells resulted in the suppression of antigen-specific CTL enhancement observed after coinjections with MCP-1 and RANTES. These results indicate that the enhancement of cytolytic activity was antigen specific and $\mathrm{CD}^{+} \mathrm{T}$ cell dependent.

Enhancement of chemokine expression. It was important to determine the effects, if any, of these specific chemokine adjuvants on chemokine production itself. We examined the expression of chemokines MIP- $1 \alpha$, RANTES, and MCP-1 by stimulated cells collected from immunized animals. Chemokine coinjection modulated chemokine production in chemokine-specific patterns. Coimmunization with chemokine cDNA cassettes resulted in increased expression of chemokines in an antigen specific manner. As shown in Fig. 10, MIP- $1 \alpha$, RANTES, or MCP-1 expression was enhanced dramatically by coimmunization with pCEnv+MIP- $1 \alpha$ pCEnv+RANTES, pCEnv+MCP-1, respectively.

\section{Discussion}

The initiation of immune or inflammatory reactions is a complex process involving a tightly coordinated expression of cel-

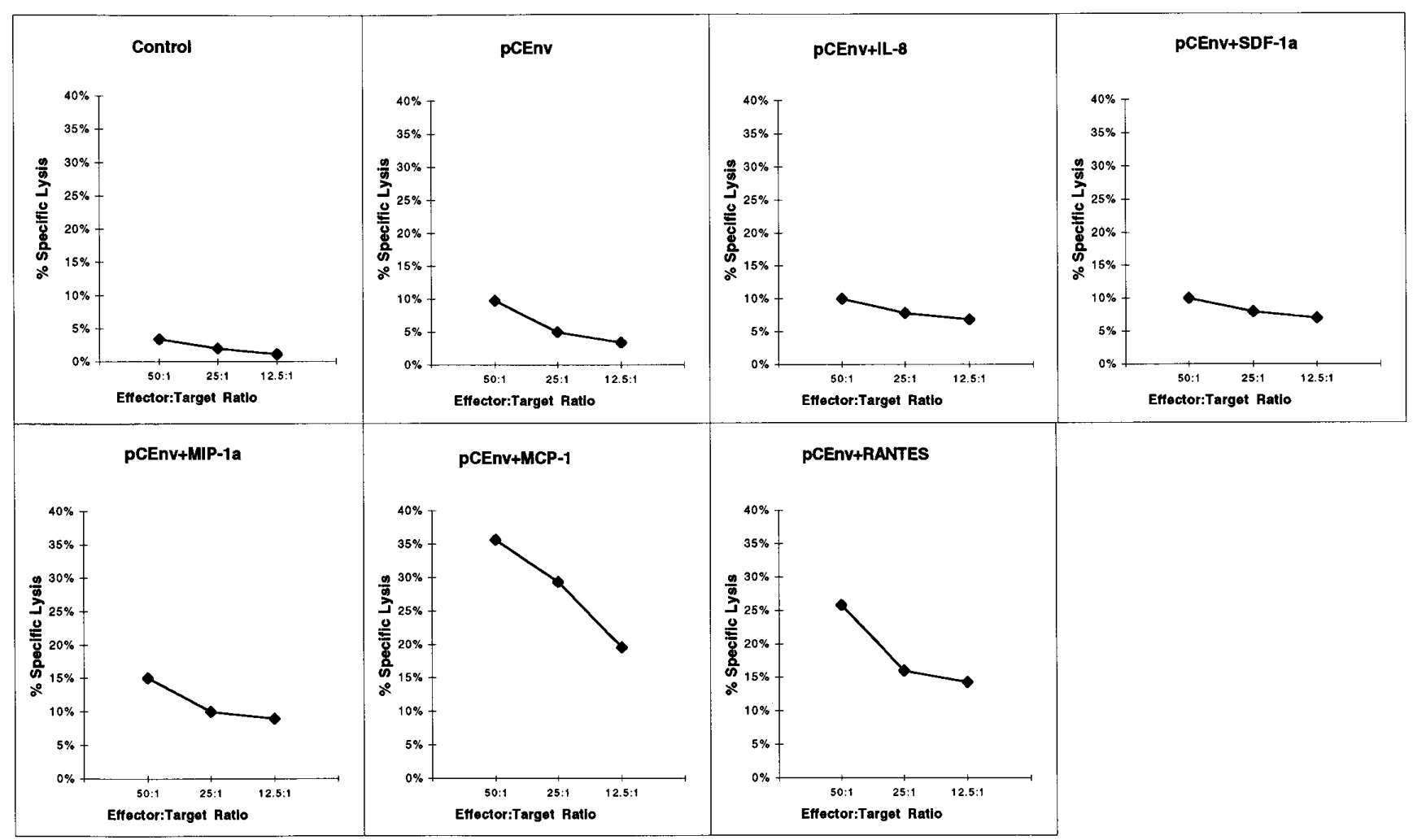

Figure 8. Determination of MHC class I-restricted CTLs. CTL assay was performed using effector cells and prepared as described, and target cells prepared with envelope-specific peptide (RIHIGPGRAFYTTKN), that has been reported to be MHC class I-restricted in Balb/c mice. These experiments have been repeated two times with similar results. 
A

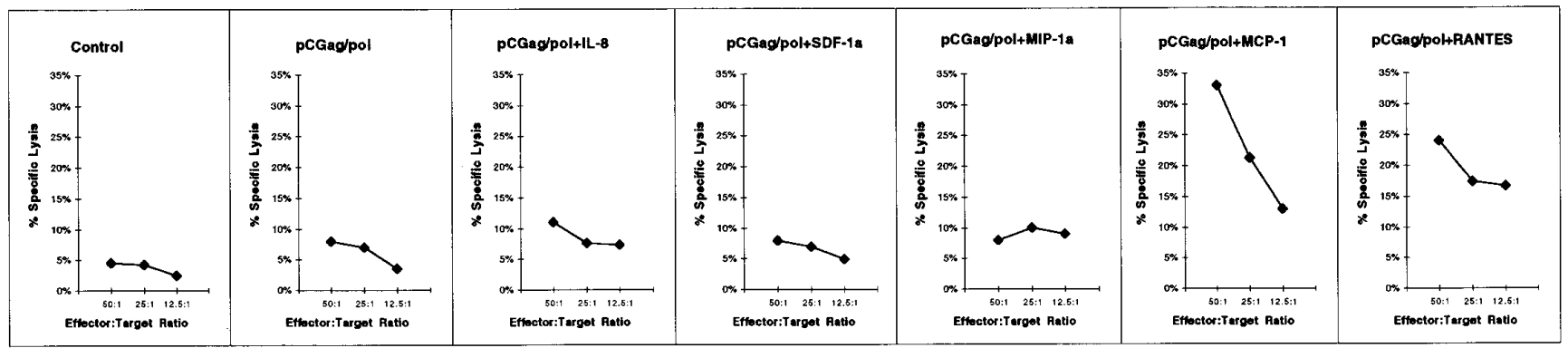

B

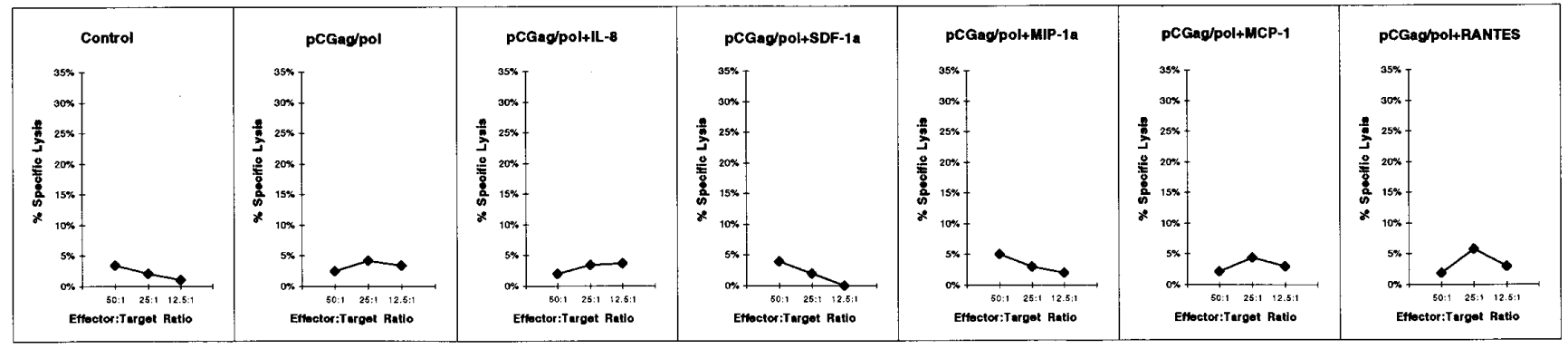

Figure 9. Determination of $\mathrm{CD} 8^{+}$-dependent CTLs. A CTL assay was performed with the removal of CD8 ${ }^{+} \mathrm{T}$ cells by complement lysis. Effector cells were prepared as described with the presence of $\mathrm{CD} 8^{+} \mathrm{T}$ cells $(A)$ and the removal of $\mathrm{CD} 8^{+} \mathrm{T}$ cells $(B)$ using vaccinia-infected target cells. These experiments have been repeated two times with similar results.

lular adhesion molecules, cytokines, and chemokines. The chemokines are especially important in the molecular regulation of trafficking of leukocytes from the lymph and blood vessels to the peripheral sites of host defense. The superfamily of chemokines consists of an array of over 30 related proteins (1). In addition to their functions in inflammatory and immune responses, some chemokines play a critical role in the transmission and progression of HIV-1 and 2 viruses responsible for AIDS. Recent studies have identified that the coreceptors required for the fusion of the $\mathrm{T}$ cell-tropic and macrophagetropic viruses with their target cells to be CXCR4 and CCR5, respectively (4-8).

To elucidate the specific roles of these chemokines in immune induction and modulation, we used the codelivery of chemokine DNA expression cassettes as an antigen delivery model. DNA coimmunization is an appropriate model to in- vestigate the in vivo functions of chemokines because DNA vaccines induce both humoral and cellular immune responses via both the MHC class I and II pathways (10, 26-29). Furthermore, we and others have shown that antigen-specific immune responses to DNA vaccines can be modulated by the coinjection of costimulatory molecule and cytokine genes with DNA immunogen cassettes $(10,11,13,30-34)$. Thus, we cloned and coimmunized chemokine expression vectors with HIV-1 DNA immunogens and examined the effects of chemokine expression on immune activation. We observed that the $\alpha$-chemokine IL- 8 and SDF- $1 \alpha$ as well as the $\beta$-chemokines MIP- $1 \alpha$, RANTES, and MCP-1 had specific, identifiable roles in the activation of antigen-specific immune responses.

For instance, IL-8 is a chemotactic factor for neutrophils, inducing them to leave the bloodstream and migrate into the surrounding tissues. We observed that IL-8 was a strong in-
A

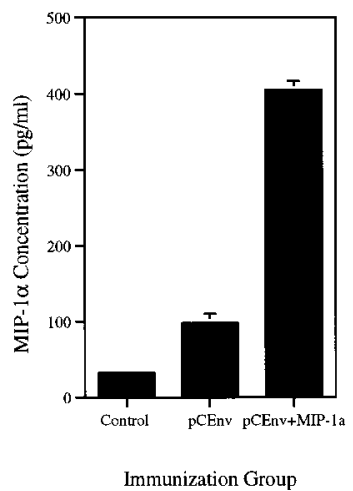

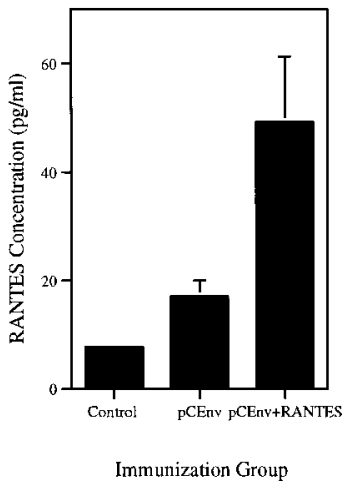

C

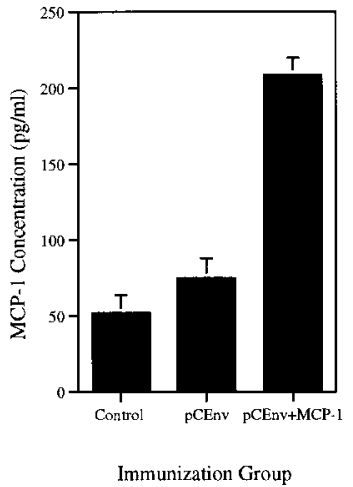

Figure 10. Expression of chemokines by stimulated effector cells. Supernatants from effectors stimulated for CTL assay were collected at day 6 and tested for cytokine profile using specific chemokine ELISA kits for MIP-1 $\alpha(A)$, RANTES $(B)$, and MCP-1 $(C)$ as described. These experiments have been repeated two times with similar results. 
ducer of $\mathrm{CD}^{+} \mathrm{T}$ cells, resulting in strong $\mathrm{T}$ helper-proliferative responses as well as increasing antibody responses. IL-8 coexpression also modulated the shift of immune responses to Th1-type, indicated by the reduction of $\operatorname{IgG} 1$ to $\operatorname{IgG} 2$ a ratio and enhanced expression of IFN- $\gamma$. On the other hand, IL-8 coadministration did not seem to have noticeable effect on $\mathrm{CD}^{+} \mathrm{T}$ cells, since it did not have any enhancement effect on the CTL response.

SDF-1 interestingly binds directly to CXCR4 receptors, which are expressed on both $\mathrm{CD}^{+}$as well as $\mathrm{CD} 8^{+} \mathrm{T}$ cells $(4$, $5)$. As this chemokine could directly interact with antigen-stimulated T cells, it was somewhat surprising to note its lack of effect on either T helper or CTL responses. The major effect observed was a shift in isotype towards a Th1 type, based on the IgG subtype ratios.

It has been reported that MIP-1 $\alpha$ can chemoattract and degranulate eosinophils (35). MIP-1 $\alpha$ also induces histamine release from basophils and mast cells and is a chemotactic factor for basophils and B cells $(36,37)$. These studies support our observation that MIP- $1 \alpha$ had the greatest effect on antibody responses. In addition, MIP- $1 \alpha$ was also a strong inducer of $\mathrm{T}$ helper-proliferative responses. MIP- $1 \alpha$ coexpression also modulated the shift of immune responses to Th2 type, indicated by the increase of $\mathrm{IgG} 1$ to $\mathrm{IgG} 2 \mathrm{a}$ ratio. In contrast, MIP$1 \alpha$ coimmunization had minimal effect on the $\mathrm{CD} 8^{+} \mathrm{T}$ cell response.

Unlike the effects of MIP- $1 \alpha$, RANTES coimmunization had minimal effect on antibody responses. RANTES is a monocyte chemoattractant. In addition, RANTES can chemoattract unstimulated $\mathrm{CD} 4^{+} / \mathrm{CD} 45 \mathrm{RO}^{+}$memory $\mathrm{T}$ cells and stimulated $\mathrm{CD}^{+}$and $\mathrm{CD}^{+} \mathrm{T}$ cells $(38-40)$. This ability of RANTES to chemoattract $\mathrm{CD}^{+}$and $\mathrm{CD}^{+}{ }^{+} \mathrm{T}$ cells to the site of DNA immunization may have been important in inducing $\mathrm{T}$ helper-proliferative responses and CTL responses. The enhanced activation of Th1 responses was supported by the increased expression of Th1 cytokines IFN- $\gamma$ and TNF- $\alpha$. The high level of CTL responses induced by RANTES expression was determined to be class I-restricted and $\mathrm{CD}^{+} \mathrm{T}$ cell dependent.

As a potent chemotactic factor for monocytes, MCP-1 is thought to be an important chemokine in chronic inflammatory disease (41). MCP-1 induces monocytes to migrate from the bloodstream to become tissue macrophages. MCP-1 was also found to chemoattract $\mathrm{T}$ lymphocytes of the activated memory subset (42). Among all chemokines examined, MCP-1 is the most potent activator of $\mathrm{CD}^{+}$CTLs. The enhancement of CTL responses induced by MCP-1 expression was determined to be class I-restricted and $\mathrm{CD} 8^{+} \mathrm{T}$ cell dependent. The enhanced CTL results are supported by increased expression of Th1 cytokines IFN- $\gamma$ and TNF- $\alpha$ and the reduction of IgG1 to $\mathrm{IgG} 2 \mathrm{a}$ ratio. Unlike RANTES, MCP-1 had positive, but moderate effect on the $\mathrm{T}$ helper cell-proliferative responses. Like RANTES, MCP-1 coadministration had no effect on antibody responses. This comparison highlights that while the induction of humoral, $\mathrm{T}$ helper, and $\mathrm{T}$ cytotoxic responses are coordinately regulated and integrated, they can be modulated independently of each other, depending on the specific environment in which the response is triggered.

In addition to their direct effects on immune responses, coexpression of chemokine genes resulted in their increased expression in autocrine manner. For instance, we observed that MIP-1 $\alpha$ expression could be enhanced dramatically by coim- munization with pCEnv+MIP-1 $\alpha$ over the level expressed by pCEnv immunization alone. Similar increases in RANTES were observed from RANTES codelivery. These results imply that these chemokines not only have a direct role in modulating immune responses, but they also amplify their effects by inducing more production of chemokines in autocrine manner. This feature could be exploited for developing immunogens that drive chemokine production as well as humoral responses to cooperatively block lentiviral infection.

An important observation was the role chemokines RANTES and MCP-1 play in inducing TNF- $\alpha$ expression. TNF- $\alpha$ is produced by activated macrophages and monocytes, neutrophils, activated lymphocytes, and NK cells (43). TNF- $\alpha$ is also implicated in septic shock after infection by Gram-negative bacteria (44) and in rheumatoid arthritis (45). Furthermore, TNF- $\alpha$ plays a pivotal role in regulating the synthesis of other proinflammatory cytokines (22). Given TNF- $\alpha$ 's critical roles in various ailments, there have been major efforts in reducing the level of TNF- $\alpha$ in vivo as potential treatment for conditions such as rheumatoid arthritis. In our experiments, we observed that coexpression of RANTES or MCP-1 resulted in the enhanced expression of TNF- $\alpha$. These results suggest that inhibiting RANTES and MCP-1 should be examined as a strategy to downregulate TNF- $\alpha$ expression in vivo.

It is of interest that Th1 vs. Th2 phenotype appears to segregate independently of other immune functions. IL- 8 boosted humoral responses but drives those responses towards a Th1 phenotype, cutting the $\mathrm{IgG} 1 / \mathrm{IgG} 2$ a ratio by almost $50 \%$ (Fig. 3 $B)$. MIP- $1 \alpha$, perhaps the most prolific driver of serology, skewed the IgG1/IgG2a ratio dramatically towards a Th2 response (Fig. 5 B). It is clear that this manipulation can allow for induction of primary antigen-specific immune responses skewed towards a desired phenotype as well as immunoglobulin isotype independently of each other. Furthermore, the induction of cellular vs. higher humoral responses appeared to be relatively polarized immune functions. Those chemokines with the most dramatic effect on humoral responses, IL-8 and MIP- $1 \alpha$, exhibited little effect on CTL responses whereas those that mediated the most dramatic effects on CTL responses, RANTES and MCP-1, had minimal effects on serology. The same CTL driving chemokines RANTES and MCP-1 both stimulated IFN- $\gamma$ and $\mathrm{TNF}-\alpha$, while the humoral responders had minimal effects on these important cytokines.

IL- 8 , SDF- $1 \alpha$, MIP-1 $\alpha$, MIP-1 $\beta$, and RANTES are products of $\mathrm{CD}^{+}$effector cells as well as other cells. Collectively, these studies demonstrate that these chemokines can function in a manner more similar to traditional Th1 or Th2 cytokines in driving and expanding immunity. For example, while MIP$1 \alpha$ can drive humoral responses, RANTES can drive CTLs. This finding suggests that $\mathrm{CD}^{+} \mathrm{T}$ cells, like $\mathrm{CD}^{+} \mathrm{T}$ cells, can play an important role, and perhaps a decisive role, in immune expansion (Fig. 11). However, this expansion generally would take place at the site of high-antigen density during effector cell function rather than in the lymphoid organs (Fig. 11). For example, as a part of active $\mathrm{CD}^{+}$effector cell function at the site of viral clearance, the local production of specific chemokines would drive expansion of humoral and/or cellular immunity until $\mathrm{CD}^{+}$CTLs eliminated their targets and ceased being activated. Since $\mathrm{CD} 8^{+} \mathrm{T}$ cells are ultimately responsible for viral clearance, it is advantageous that they would control immune responses at the front line battle site as they have the specific machinery to determine when the invading pathogen 


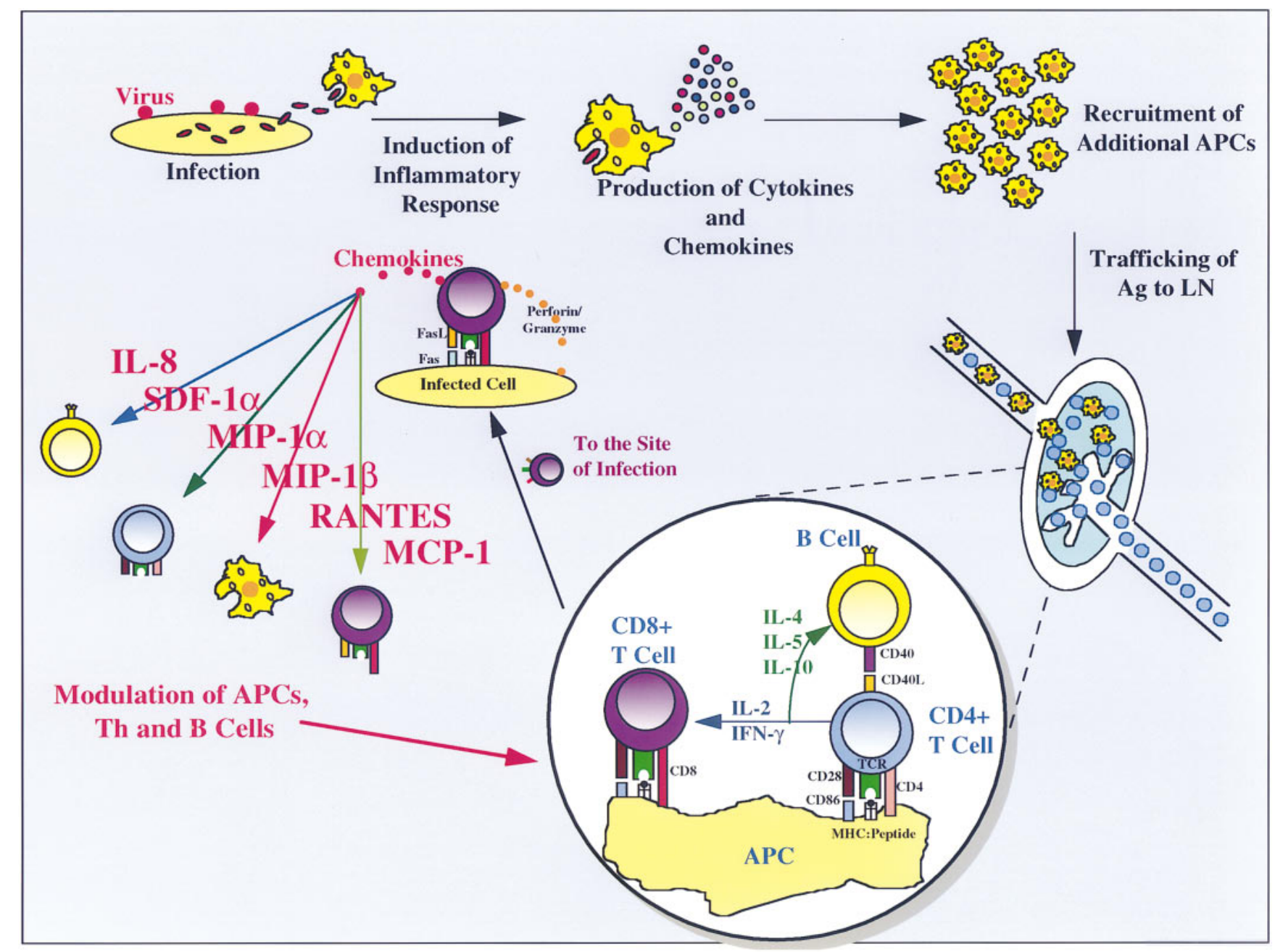

Figure 11. A summary of immune expansion mediated by chemokines and CD8 ${ }^{+} \mathrm{T}$ cells. As a part of active effector cell function in the periphery, activated $\mathrm{CD} 8^{+}$CTLs produce specific chemokines which drive immune expansion.

has been cleared. The site of immune expansion would distinguish this regulatory role from the role of $\mathrm{CD} 4^{+} \mathrm{T}$ cells that require APCs and class II presentation to assert their role in immune regulation. In contrast, peripheral CTL action requires only class I presentation that can be achieved by non-APCs. How and if CD8 effector cells segregated into "Th1 versus Th2 chemokine" producing cells is a subject for future investigation.

These results outline a key regulatory role for $\mathrm{CD}^{+}$effector cells in the expansion phase of an antigen-specific immune response in the periphery. Better understanding of the mechanism of immune expansion could have important implication for the design of vaccines and immune therapies.

\section{Acknowledgments}

We wish to thank R. Ciccarelli from WLVP for thoughtful discussion and providing material for this study. We would like to thank $\mathrm{H}$. Lee and D. Cunning for helpful technical assistance. J.J. Kim would like to thank G. Feiler, J. Dingerdissen, and V. Samant.

This work was supported in part by grants from National Institutes of Health to D.B. Weiner and M.G. Agadjanyan.

\section{References}

1. Baggiolini, M., D. Beatrice, and B. Moser. 1997. Human chemokines: an update. Annu. Rev. Immunol. 15:675-705.

2. Schall, T.J., and K.B. Bacon. 1994. Chemokines, leukocyte traficking, and inflammation. Curr. Opin. Immunol. 6:865-873.

3. Murphy, P.M. 1994. The molecular biology of leukocyte chemoattractant receptors. Annu. Rev. Immunol. 12:593-633.

4. Bleul, C.C., M. Farzan, H. Choe, C. Parolin, I. Clark-Lewis, J. Sodroski, and T.A. Springer. 1996. The lymphocyte chemoattractant SSDF-1 is a ligand for LESTR/fusin and blocks HIV-1 entry. Nature. 382:829-832.

5. Oberlin, E., A. Amara, F. Bachelerie, C. Bessia, J.-L. Virelizier, F. arenzana-Seisdedos, O. Schwartz, J.-M. Heard, I. Clark-Lewis, D.F. Legler, et al. 1996. The CXC chemokine SDF-1 is the ligand for LESTR/fusin and prevents infection by T-cell-line-adapted HIV-1. Nature. 382:833-835.

6. Cocchi, F., A.L. DeVico, A. Garzino-Demo, S.K. Arya, R.C. Gallo, and P. Lusso. 1995. Identification of RANTES, MIP-1a, and MIP-1b as the major HIV-suppressive factors produced by CD8 ${ }^{+}$T cells. Science. 270:1811-1815.

7. Deng, H.K., R. Liu, W. Ellemeier, S. Choe, D. Unutmaz, M. Burkhart, P. Di Marzio, S. Marmon, R.E. Sutton, C.M. Hill, et al. 1996. Identification of a major co-receptor for primary isolates of HIV-1. Nature. 381:661-666.

8. Alkhatib, G., C. Combadiere, C.C. Boder, Y. Feng, P.E. Kennedy, P.M Murphy, and E.A. Berger. 1996. CC CKR5: A RANTES, MIP-1a, MIP-1b receptor as a fusion cofactor for macrophage-tropic HIV-1. Science. 272:19551958.

9. Boyer, J.D., K.E. Ugen, B. Wang, M.G. Agadjanyan, L. Gilbert, M. Bagarazzi, M. Chattergoon, P. Frost, A. Javadian, W.V. Williams, et al. 1997. Protection of chimpanzees from high-dose heterologous HIV-1 challenge by DNA vaccination. Nat. Med. 3:526-532. 
10. Kim, J.J., M.L. Bagarazzi, N. Trivedi, Y. Hu, M.A. Chattergoon, K. Dang, S. Mahalingam, M.G. Agadjanyan, J.D. Boyer, B. Wang, et al. 1997. Engineering of in vivo immune responses to DNA immunization via co-delivery of costimulatory molecule genes. Nat. Biot. 15:641-645.

11. Kim, J.J., N.N. Trivedi, L. Nottingham, L. Morrison, A. Tsai, Y. Hu, S. Mahalingam, K. Dang, L. Ahn, N.K. Doyle, et al. 1998. Modulation of amplitude and direction of in vivo immune responses by co-administration of cytokine gene expression cassettes with DNA immunogens. Eur. J. Immunol. 28: 1089-1103.

12. Takahashi, H., Y. Nakagawa, C.D. Pendleton, R.A. Houghten, K. Yokomuro, R.N. Germain, and J.A. Berzofsky. 1992. Induction of broadly cross-reactive cytotoxic T cells recognizing an HIV-1 envelope determinant. Science. 255:333-336.

13. Kim, J.J., V. Ayyvoo, M.L. Bagarazzi, M.A. Chattergoon, K. Dang, B. Wang, J.D. Boyer, and D.B. Weiner. 1997. In vivo engineering of a cellular immune response by co-administration of IL-12 expression vector with a DNA immunogen. J. Immunol. 158:816-826.

14. Callard, R., and A. Gearing. 1994. The Cytokine FactsBook. Academic Press Limited, London. 265 pp.

15. Skerka, C., S.G. Irving, A. Bialonski, and P.F. Zipfel. 1993. Cell type specific expression of members of the IL-8/NAP-1 gene family. Cytokine. 5: $112-116$

16. Wechsler, A.S., M.C. Gordon, U. Dendorfer, and K.P. LeClair. 1994. Induction of IL-8 expression in T cells uses the CD28 costimulatory pathway. $J$. Immunol. 153:2515-2123.

17. Qin, S.X., G. LaRosa, J.J. Campbell, H. Smith-Heath, N. Kassam, X.J. Shi, L. Zeng, E.C. Butcher, and C.R. Mackay. 1996. Expression of monocyte chemoattractant protein-1 and interleukin- 8 receptors in subsets of T cells: correlation with transendothelial chemotactic potential. Eur. J. Immunol. 26:640647.

18. Chuntharapai, A., J. Lee, C.A. Hebert, and K.J. Kim. 1994. Monoclonal antibodies detect different distribution patterns of IL-8 receptor A and IL-8 receptor B on human peripheral blood leukocytes. J. Immunol. 153:5682-5688.

19. Finkelman, F.D., J. Holmes, I.M. Katona, J.F. Urban, M.P. Beckmann, L.S. Park, K.A. Schooley, R.L. Coffman, T.R. Mosmann, and W.E. Paul. 1990. Lymphokine control of in vivo immunoglobulin isotype selection. Ann. Rev. Immunol. 8:303-333.

20. Mogensen, S.C., and J.L. Virelizier. 1987. The interferon-macrophage alliance [Review]. Interferon. 8:55-84.

21. Seder, R.A., and W.E. Paul. 1994. Acquisition of lymphokine-producing phenotype by $\mathrm{CD}^{+}$T cells. Annu. Rev. Immunol. 12:635-673.

22. Arend, W.P., and J.M. Dayer. 1995. Inhibition of the production and effects of interleukin-1 and tumor necrosis factor a in rheumatoid arthritis. Arthritis Rheum. 38:151-160.

23. Loetscher, M., T. Geiser, T. O'Reilly, R. Zwahlen, M. Baggiolini, and B. Moser. 1994. Cloning of a human seven-membrane domain receptor, LESTR, that is highly expressed in leukocytes. J. Biol. Chem. 269:232-237.

24. Choe, H., M. Farzan, Y. Sun, N. Sullivan, B. Rollins, P.D. Ponath, L. Wu, C.R. Mackay, G. LaRosa, W. Newman, et al. 1996. The b-chemokine receptor CCR3 and CCR5 facilitate infection by primary HIV-1 isolates. Cell. 85: $1135-1148$.

25. Doranz, B.J., J. Rucker, Y. Yi, R.J. Smyth, M. Samson, S.C. Peiper, M. Parmentier, R.G. Collman, and R.W. Doms. 1996. A dual-tropic primary HIV-1 isolate that uses fusin and the b-chemokine receptors CKR-5, CKR-3, and CKR-2b as fusion cofactors. Cell. 85:1149-1158.

26. Wolff, J.A., R.W. Malone, P. Williams, W. Chong, G. Acsadi, A. Jani, and P.L. Felgner. 1990. Direct gene transfer into mouse muscle in vivo. Science. 247:1465-1468.

27. Tang, D., M. DeVit, and S. Johnston. 1992. Genetic immunization is a simple method for eliciting an immune response. Nature. 356:152-154.

28. Wang, B., K.E. Ugen, V. Srikantan, M.G. Agadjanyan, K. Dang, Y. Refaeli, A. Sato, J. Boyer, W.V. Williams, and D.B. Weiner. 1993. Gene inocula- tion generates immune responses against human immunodeficiency virus type 1. Proc. Natl. Acad. Sci. USA. 90:4156-4160.

29. Ulmer, J.B., J. Donnelly, S.E. Parker, G.H. Rhodes, P.L. Felgner, V.L. Dwarki, S.H. Gromkowski, R. Deck, C.M. DeVitt, A. Friedman, et al. 1993. Heterologous protection against influenza by injection of DNA encoding a viral protein. Science. 259:1745-1749.

30. Kim, J.J., and D.B. Weiner. 1997. DNA/genetic vaccination for HIV. Springer Semin. Immunopathol. 19:174-195.

31. Iwasaki, A., B.J. Stiernholm, A.K. Chan, N.L. Berstein, and B.H. Barber. 1997. Enhanced CTL responses mediated by plasmid DNA immunogens encoding costimulatory molecules and cytokines. J. Immunol. 158:4591-4601.

32. Raz, E., A. Watanabe, S.M. Baird, R.A. Eisenberg, T.B. Parr, M. Lotz, T.J. Kipps, and D.A. Carson. 1993. Systemic immunological effects of cytokine genes injected into skeletal muscle. Proc. Natl. Acad. Sci. USA. 90:4523-4527.

33. Xiang, Z., and H.C. Ertl. 1995. Manipulation of the immune response to a plasmid-encoded viral antigen by coinoculation with plasmids expressing cytokines. Immunity. 2:129-135.

34. Tsuji, T. K. Hamajima, N. Ishii, I Aoki, J. Fukushima, K Q Xin, S. Kawamoto, S. Sasaki, K. Matsunaga, Y. Ishigatsubo, et al. 1997. Immunomodulatory effects of a plasmid expressing B7-2 on human immunodeficiency virus1-specific cell-mediated immunity induced by a plasmid encoding the viral antigen. Eur. J. Immunol. 27:782-787.

35. Rot, A., and M. Krieger, T. Brunner, S.C. Bischoff, T.J. Schall, and C Dahinden. 1992. RANTES and macrophage inflammatory protein 1 alpha induce the migration and activation of normal human eosinophil granulocytes. $J$. Exp. Med. 176:1489-1495

36. Alam, R., P.A. Forsythe, S. Stafford, M.A. Lett-Brown, and J.A. Grant 1992. Macrophage inflammatory protein-1 alpha activates basophils and mast cells. J. Exp. Med. 176:781-786.

37. Schall, T.J., K. Bacon, R.D. Camp, J.W. Kaspari, and D.V. Goeddel. 1993. Human macrophage inflammatory protein alpha (MIP-1 alpha) and MIP-1 beta chemokines attract distinct populations of lymphocytes. J. Exp. Med. 177: 1821-1826.

38. Schall, T.J., K. Bacon, K.J. Toy, and D.V. Goeddel. 1990. Selective attraction of monocytes and $\mathrm{T}$ lymphocytes of the memory phenotype by cytokine RANTES. Nature. 347:669-671.

39. Murphy, W.J., D.D. Taub, M. Anver, K. Conlon, J.J. Oppenheim, D.J. Kelvin, and D.L. Longo. 1994. Human RANTES induces the migration of human $\mathrm{T}$ lymphocytes into the peripheral tissues of mice with severe combined immune deficiency. Eur. J. Immunol. 24:1823-1827.

40. Meurer, R., G. Van Riper, W. Feeney, P. Cunningham, D. Hora, Jr., M.S. Springer, D.E. MacIntyre, and H. Rosen. 1993. Formation of eosinophilic and monocytic intradermal inflammatory sites in the dog by injection of human RANTES but not human monocyte chemoattractant protein 1, human macrophage inflammatory protein 1 alpha, or human interleukin 8. J. Exp. Med. 178:1913-1921.

41. Matsushima, K., E.T. Baldwin, and N. Mukaida. 1992. Interleukin-8 and MCAF: novel leukocyte recruitment and activating cytokines. Chem. Immunol. 51:236-265.

42. Carr, M.W., S.J. Roth, E. Luther, S.S. Rose, and T.A. Springer. 1994. Monocyte chemoattractant protein 1 acts as a T-lymphocyte chemoattractant Proc. Natl. Acad. Sci. USA. 91:3652-3656.

43. Vilcek, J., and T.H. Lee. 1991. Tumor necrosis factor. New insights into the molecular mechanisms of its multiple actions. [Review]. J. Biol. Chem. 266: $7313-7316$.

44. Tracey, K.J., Y. Fong, D.G. Hesse, K.R. Manogue, A.T. Lee, G.C. Kuo, S.F. Lowry, and A. Cerami. 1987. Anti-cachectin/TNF monoclonal antibodies prevent septic shock during lethal bacteraemia. Nature. 330:662-664.

45. Yocum, D., L. Esparza, S. Dubry, J. Benjamin, R. Volz, and P. Scuderi. 1989. Characteristics of tumor necrosis factor production in rheumatoid arthritis. Cell. Immunol. 122:131-145. 